\title{
Shared information as a resource for the development of ideas: An EM/CA and DC analysis
}

\author{
BRIAN DUE
}

This paper discusses how participants during meetings in Danish organizations generate new ideas via a number of local semiotic resources. The article draws on Distributed Cognition (DC) (Hutchins 1995) as theoretical background of what constitutes an activity system and utilizes multimodal Ethno-Methodological Conversation Analysis (EM/CA) as a specific method for analysis. The article contributes partly with new knowledge about how cognition is embedded in the idea development operations and also how ideas are created sequentially, simultaneously and multimodally. The article specifically shows how "conceptual formulations" are a resource for the development of ideas. The article exemplifies how DC and EM/CA together can be used analytically. 